\title{
Las decimonónicas ideas del legislador ecuatoriano: política criminal y dolo en la reforma al COIP
}

\author{
The nineteenth-century ideas of the Ecuadorian \\ legislator: criminal policy and intent on COIP reform
}

\author{
Víctor Vicente Vásconez Merelo \\ Investigador jurídico independiente \\ Abogado penalista \\ Ciudad: Quito \\ País: Ecuador
}

Artículo original (investigación)

RFJ, No. 7, 2020, pp. 246-267, ISSN 2588-0837

RESUMEN: Lejos se encuentra la política criminal ecuatoriana de cumplir con estándares adecuados de cientificidad, pues el político de turno parece legislar con el diario de ayer en la mano. En esta obra se critica dos cuestiones en especial: en primer lugar, se destaca la contradictoria política criminal del legislador ecuatoriano al decantarse sobre una de las teorías del dolo más garantistas que existen y al mismo tiempo, esto es, en el mismo cuerpo legal reformatorio, se legisla el adefesio legislativo de exponer a la luz pública a quien haya sido aprehendido en delito (los delitos de moda) flagrante y así el juez lo haya convalidado. En segundo lugar, es decir, en el capítulo II de la obra, se analiza críticamente las falencias de la teoría de la voluntad del dolo que fue adoptada por el legislador, en conjunto con el análisis crítico del resto de teorías que dominan la discusión científica en la actualidad. Finalmente, se concluirá que el legislador fue abiertamente contradictorio en su política criminal y que, la teoría de la voluntad del dolo si bien ofrece un respeto altísimo a la dignidad del ser humano y por ello se constituye como la teoría más garantista, esto no significa que, en términos teóricos, ni procesales, sea la teoría más racional e idónea por la que pudo haberse inclinado el legislador ecuatoriano. 
PALABRAS CLAVE: Legislador, política criminal, exposición a la luz pública, presunción de inocencia, teoría de la voluntad del dolo.

\begin{abstract}
Far away is the Ecuadorian criminal policy of complying with adequate standards of scientificity. Then as the politician on duty seems to legislate with yesterday's newspaper in his hand. In this paper, two issues are criticized in particular. First, the contradictory criminal policy of the Ecuadorian legislator is highlighted by taking sides with one of the most guaranteed theories of men's rea of intent. At the same time, in the same legal body Reform, the legislature is legislated to expose to public light, which has been apprehended in flagrant crime (fashion crimes), and thus the judge has validated. Secondly, that is, in the second chapter of the work, the failures of the theory of the will of men's rea that was adopted by the legislator are analyzed critically, together with the critical analysis of the rest of theories that dominate the scientific discussion nowadays. Finally, it will be concluded that the legislator was openly contradictory in his criminal policy and that the theory of the will of men's rea. However, it offers very high respect for the dignity of the human being, and that is why it constitutes the most guarantee theory, this does not mean that in theoretical or procedural terms, it is the most rational and suitable for which the Ecuadorian legislator could have inclined.
\end{abstract}

KEYWORDS: Legislator, criminal policy, exposure to the public light, violation of the presumption of innocence, Thymus will theory, men's rea.

\title{
INTRODUCCIÓN
}

El 24 de diciembre del año 2019 el legislador ecuatoriano en el uso de sus facultades introdujo una reforma al Código Orgánico Integral Penal. Como ya es costumbre, algunas de las decisiones que fueron tomadas resultaron en el mejor de los casos polémicas, puesto que según las apreciaciones de cualquier jurista concienzudo se avizora no solo inconsistencias, 
sino también la utilización de teorías dogmáticas que ya fueron superadas en la discusión doctrinal.

En tal circunstancia, en primer lugar, la obra que continúa tiene por finalidad poner sobre la mesa una severa contradicción político-criminal del legislador, puesto que en relación al dolo se decanta por la teoría de la voluntad, que sin ser la mayoritaria en la doctrina en razón de múltiples problemas, a mi juicio es la que ofrece mayor respecto a la dignidad del ser humano; sin embargo, en el mismo cuerpo reformatorio también se legisla que el ciudadano que sea aprehendido por delito flagrante en delitos contra la inviolabilidad de la vida, la integridad sexual y reproductiva, violencia contra la mujer o miembros del núcleo familiar y los delitos de robo con muerte, sicariato, trata de personas y tráfico de migrantes, serán expuestos a la luz pública por el solo hecho de que un juez califique la legalidad de la aprehensión. Como es evidente, todo el garantismo mostrado en la selección de la teoría del dolo se vino abajo cuando se introdujo dicha norma que lesiona frontalmente la garantía de ser tratado como inocente hasta que exista una condenatoria ejecutoriada, lo que trae aparejado una vulneración irreversible a la dignidad de los ciudadanos.

Finalmente, y como ya se había dicho, la teoría del dolo por la que se inclinó el legislador ecuatoriano ha sido superada en la doctrina dominante. Por tanto, en lo que sigue también se estudiará las características de las principales teorías del dolo que se encuentran pugnando por ser dominantes, para concluir con una apreciación - muy personal- del motivo que orilló al legislador ecuatoriano a elegir la teoría de la voluntad del dolo pese a ser minoritaria en la doctrina y mi posición personal sobre los elementos constitutivos del dolo.

\section{LA CONTRADICTORIA POLÍTICA CRIMINAL EN EL ECUADOR}

Existen dos formas de legislar en un Estado, en la primera de ellas el Estado se auto percibe hiperpoderoso y así lo resalta en cada decisión política, bajo esta modalidad de gobierno el "yo" prácticamente se desvanece, puesto que el "nosotros" sirve 
de fundamento para que el Estado legisle con el supuesto fin proclamado del bienestar comunitario; por supuesto que esto solo sirve de cimiento para legislar de la manera más severa. Cuando el "yo" desaparece, también lo hacen consigo o por lo menos se ven menoscabadas las garantías individuales, en razón de que es inaceptable que un fin individual pueda sobreponerse a uno colectivo; es esta forma de pensamiento que de a poco reduce al hombre y a su importantísima dignidad en una mera masa mecánica encaminada a cumplir fines trazados por un anónimo. Así también lo conciben Zaffaroni, Slokar y Alagia (2002), quienes resaltan que según esta forma de legislar "lo importante es el cuerpo social (...) es el verdadero objeto de atención, pues las personas son meras células que, cuando son defectuosas y no pueden corregirse, deben eliminarse." (p. 64).

En tal circunstancia, la superposición del "nosotros" tiene un fundamento estrictamente organicista, es decir que el Estado entiende a los ciudadanos como partes integradoras -por supuesto intercambiables- de un sistema complejo en el que el mismo Estado es la cabeza y como tal, es quien ordena cada movimiento que se debe ejecutar. Desde luego, este modelo de Estado no parece del todo desconocido, pues solo en el siglo pasado, esto es, en 1922 (Italia), 1934 (Alemania) y 1939 (España), el fascismo se disfrazó de "modelo democrático" para cometer los peores crímenes en la historia de la humanidad. Por tanto, bajo esta perspectiva aberrante del poder, resulta inconcebible reconocerles a los ciudadanos derechos y garantías individuales para que puedan auto determinarse, y es más peligroso todavía, cuando dicha forma de entender el poder irrumpe en todos los poderes del Estado menoscabando así los derechos y garantías en el marco de procedimientos judiciales.

Por otro lado, en tanto que existen "Estados" organicistas o mejor dicho autoritarios, también existen verdaderos Estados. En el marco de la regulación de libertades de los ciudadanos, estos Estados se caracterizan por que su norte es la armonía entre los intereses comunitarios y los individuales; consecuentemente, toda restricción que se aspire imponer deberá superar un elevado estándar de legitimidad y esto solo puede darse en un modelo de Derecho penal mínimo. (Ferrajoli, 2004, p. 242). Suele denominarse a este tipo de Estados como garantistas, y 
paradójicamente no se utiliza este término como un adjetivo positivo, sino que, es un término usado peyorativamente por quienes en general miran con malos ojos que los ciudadanos gocen de algunos derechos y garantías esenciales en el marco de un proceso penal, como la presunción de inocencia, el derecho a la defensa en el marco de un proceso judicial, etc. Más bien, los "antigarantistas" abogan por un Estado que utilice mano dura al momento de regular la vida de los hombres en sociedad y sobre todo cuando de castigo se trata.

Los fanes de que se utilice mano dura estatal en el castigo, generalmente parten de una premisa errónea que incluso parece ser hasta descabellada. Se dice que las garantías constitucionales de los artículos 76 y 77 de la Constitución Nacional, en consuno con las garantías del debido proceso prescritas desde el libro segundo en el Código Orgánico Integral Penal (en adelante COIP), no son más que formas de encubrir y hasta fomentar el incumplimiento de normas. Sin embargo, los amigos "antigarantistas" parecen olvidar cuán peligroso puede resultar un Estado omnipresente que posiblemente se desboque en razón del poder concentrado; por ello, gozar de garantías y derechos lato sensu nos asegura el respecto de nuestra dignidad como seres humanos libres, con mayor razón si nos situamos en un contexto judicial de carácter penal, pues allí toda la estantería del Estado recae sobre los hombros de quién está siendo investigado y como tal, es en demasía importante garantizar el respeto de derechos. Por todo esto, no son coincidencia las palabras de Zaffaroni, et. Al. (2002) al decir que: "La historia enseña que la. dignidad humana, cuando avanza, lo hace en lucha contra el sistema penal. Casi podría decirse que la humanidad avanzó siempre en pugna con éste." (p. 45).

Entonces bien, si acordamos que un verdadero Estado debe ser aquel que es garante de los derechos y garantías de sus ciudadanos, también debemos acordar que dicho Estado debe ser coherente en su política criminal, puesto que una mixtura de criterios contradictorios solo daría pie a que exista gran confusión en los ciudadanos y, además, generaría un peligroso salvoconducto para quienes todavía tienen en mente un proyecto 
de sociedad filo fascista. Dicho esto, es pertinente trazar un parangón entre dos figuras jurídicas que fueron legisladas en la última reforma del COIP y de esa manera concluir si el mensaje legislativo es coherente, o a su vez, convergen ideas autoritarias $\mathrm{y}$ garantistas.

En primer lugar, en el artículo seis de la Ley Orgánica reformatoria al COIP, se prescribe expresamente el concepto de dolo, esto no quiere decir que bajo la anterior redacción no haya quedado claro cuál era la teoría del dolo por la que se había decantado el legislador; sin embargo, esta vez se optó por dejarla sentada explícitamente. Antes de la reforma, el legislador había dicho que actúa con dolo quién tenga el designio de causar daño, por lo que a todas luces se había adoptado la teoría de la voluntad del dolo pese a la terminología exiguamente técnica. Sobre el concepto de dolo siguiendo la teoría de la voluntad, enseña Welzel (1956) que toda acción consciente es llevada a cabo por "la decisión de acción, es decir, por la conciencia de lo que se quiere -el elemento intelectual-, y la decisión de querer realizarlo -el elemento volitivo-. Ambos elementos juntos, como factores creadores de una acción real constituyen el dolo". (p. 73). En suma, cuando la norma hacía alusión al "designio" de causar daño, este concepto necesariamente traía aparejado tener consciencia y voluntad de ejecutar una conducta. Aúna con este criterio la definición que le da la Real Academia Española (2001) a la palabra "designio", pues se la concibe como: "Pensamiento, o propósito del entendimiento, aceptado por la voluntad".

Dicho esto, en la reforma legislativa del 24 de diciembre de 2019 se estipula que actúa con dolo la persona que, conociendo los elementos objetivos del tipo penal, ejecuta voluntariamente la conducta, por lo que, palabras más, palabras menos, sigue siendo la misma fórmula adoptada con anterioridad, es decir, la teoría de la voluntad del dolo. Ahora bien, dicho a grosso modo en razón de que en capítulos venideros se le dará un estudio más exhaustivo, la teoría de la voluntad del dolo es la que más se ajusta al respeto de la dignidad del ser humano, puesto que solo las conductas que sean guiadas por el conocimiento y voluntad de realización serán relevantes para el Derecho penal. Por tanto, 
es plausible argumentar que la adopción de esta teoría se condice con las exigencias de un Estado democrático garantista, lo cual no significa que, en términos de política criminal y necesidad sea la teoría acertada, y así lo concibe la doctrina mayoritaria al decantarse por la teoría del conocimiento o representación.

Con este marco a prima facie garantista respecto de la teoría del dolo adoptada por el legislador ecuatoriano, verdaderamente es un contrasentido lo prescrito en el primer inciso del artículo ochenta y siete de la Ley Orgánica reformatoria al COIP, en donde reza lo siguiente:

La persona aprehendida por delitos contra la inviolabilidad de la vida, delitos contra la integridad sexual y reproductiva, delitos de violencia contra la mujer o miembros del núcleo familiar y los delitos de robo con muerte, sicariato, trata de personas y tráfico de migrantes, podrá ser identificada físicamente ante la comunidad y ante los medios de comunicación, única y exclusivamente en su calidad de aprehendido y siempre y cuando se haya calificado la legalidad de la aprensión por delito flagrante.

Como es evidente, la disposición prescrita lesiona frontalmente el derecho a la presunción de inocencia; sin embargo, el legislador de forma muy llamativa arguye en el inciso siguiente que "en estos casos se respetará el derecho constitucional de la persona a que se presuma su inocencia y a ser tratada como tal, mientras no se declare su responsabilidad mediante sentencia ejecutoriada." De un análisis conglobado del artículo 87 de la Ley reformatoria se desprende que no hay manera posible en la que se respete el derecho a la inocencia y ser tratado como tal si previamente se ha divulgado y catalogado a un ciudadano como posible delincuente, pues la presión mediática, el prejuicio en cabeza de juzgadores y fiscales jugará un papel nocivo en el momento de arribar a una decisión judicial.

Hay que señalar que el derecho a la presunción de inocencia comprende además el derecho a ser tratado como tal, tanto en instancia judicial como también en el normal desarrollo de la vida en sociedad., y es por esto que, "a partir de ella y 
sobre ella comienza a construirse el escudo protector frente al poder arbitrario, que es el cometido de todas las garantías que juegan en el proceso penal." (Binder, 1999, p. 123). Por tanto, quién funja en calidad de procesado en uno de los delitos mencionados por la norma, será muy difícil que pueda gozar de aceptación social luego de que su hipotético crimen haya sido expuesto a la luz pública, tomando en consideración que el solo hecho de que se aprehenda a una persona en delito flagrante no es base suficiente para determinar su responsabilidad penal. En suma, no solo es una decisión legislativa arbitraria, sino que, constituye además una política criminal propia de un Estado absolutista, autoritario y en demasía irracional. Veamos un ejemplo para esclarecer este punto:

Digamos que $\mathrm{X}$ es asesinado en la Av. 10 de agosto y José Falconí, el supuesto criminal no es captado por cámaras, sino que, únicamente existen indicios de su identificación a través de los testimonios de los ciudadanos que presenciaron el hecho. Los testigos aducen que el criminal habría estado vestido con jean y camisa amarilla, además era alto, delgado y con cabello largo. Con este contexto, siendo que la realidad suele ser mucho más expresiva y sorpresiva que la fantasía, justamente aprehenden 7 horas después del hecho a un ciudadano que respondía a esas características; de inmediato se practica la audiencia de calificación de flagrancia y efectivamente el juzgador decide validarla. Acto seguido las autoridades proceden a exhibir los datos personales del supuesto delincuente y los medios de comunicación le dedican un especial en horario estelar como suelen hacerlo. De esta forma, nuestro hipotético criminal ha sido encasillado, identificado y expuesto, lo cual significa no solo un menoscabo en su honra, sino que, además conlleva un detrimento psicológico mayúsculo en su humanidad y en la familia de este.

Durante la instrucción fiscal, nuestros brillantes investigadores descubren que el ciudadano hipotético habría coincidido en tiempo y espacio conjuntamente con las similitudes físicas, pero que él no habría sido quién cometió la infracción. Acto seguido, se le concede la libertad al ciudadano por habérsele dictado prisión preventiva, y el Estado fácil y sencillo se olvida de aquel desgraciado. 
Cualquier hombre de leyes u hombre común y corriente seguramente tendrá una sensación de que el ciudadano expuesto fue víctima de un sin número de vulneraciones a sus derechos. No hay que ser experto en Derecho penal, tampoco en Criminología y menos aún en Política Criminal para evidenciar que supuestos de esta naturaleza pueden ocurrir y lesionarse el derecho a la dignidad, a la honra y buen nombre, al trabajo y un sinfín de derechos constitucionales y convencionales. Sin embargo, el brillante legislador y quienes están en al mando parecen olvidar que el poder punitivo opera a discreción y tarde o temprano quienes apuntan con el dedo también podrán ser apuntados, solo basta mirar el número de políticos criminalizados para corroborar dicha premisa.

En fin, por un lado, el legislador procuró ser lo más garantista posible al decantarse por la teoría de la voluntad del dolo y, por otro lado, de forma muy autoritaria se inclinó por legislar al puro estilo del siglo XVIII en donde se exponía a los criminales en el patíbulo para que todos los pobladores puedan observar su castigo y supuestamente generar una coacción y con ello una abstención de cometer infracciones. Seguramente Feuerbach (1989) estaría satisfecho al observar que doscientos años después en un país pequeñito y con alto nivel de analfabetismo se adoptó su teoría de la pena de prevención general negativa. (p. 8).

\section{EL DOLO EN EL CÓDIGO ORGÁNICO INTEGRAL PENAL Y EN LA DOCTRINA DOMINANTE}

Desde que la escuela Causalista fue totalmente superada en la dogmática jurídico-penal, el llamado dolus malus se escindió y se trasladó el conocimiento y voluntad de realizar los elementos objetivos del tipo penal hacia la tipicidad y la culpabilidad conservó el conocimiento de la antijuridicidad de la conducta. En igual sentido, Plascencia Villanueva (2004) argumento lo siguiente:

El dolo y la culpa constituyen, en términos del estado actual de la evolución de la dogmática penal, elementos del tipo penal, lugar resultante de su ubicación a nivel 
de la acción por parte de la teoría final de la acción, la cual hoy se percibe como dominante en la dogmática penal, cuestión por la que debemos desterrar todo planteamiento que pretenda analizarlo como forma, especie o elemento de la culpabilidad. (p. 113).

Desde allí, básicamente han sido tres las teorías del dolo que han sobresalido en la doctrina y que hoy en día se disputan protagonismo en un sistema jurídico altamente complejo en razón del desarrollo de las nuevas tecnologías y las formas de vivir en sociedad. Veamos a continuación:

* Teoría de la voluntad. - esta teoría prácticamente germinó con la noción del concepto personal del injusto ideada por Hans Welzel (1956), pues el brillante autor alemán argüía que la teoría del injusto "se llena así cada vez más, de elementos psíquicos, que en su origen fueron asignados erróneamente a la teoría de la culpabilidad: primero con los elementos subjetivos de lo injusto, luego con la voluntad de acción" (p. 151). Si se parte de la idea de que el hombre únicamente comete un injusto penal en la medida en que haya direccionado su voluntad conscientemente hacia el quebrantamiento de la norma, la consecuencia directa de este primer planteamiento sería que el dolo se vea conformado por los mismos elementos; es decir, para la teoría de la voluntad, el dolo tiene que comprender una faz cognitiva y otra volitiva.

El elemento cognitivo del dolo se refiere al conocimiento que tenga el individuo sobre los elementos objetivos del tipo penal, hay que destacar que dicho conocimiento debe ser actual, es decir que existe una prohibición de tomar en consideración un dolo inicial (antecedens) o uno subsiguiente (subsequens) a la ejecución de la conducta. Además, como es natural, existen elementos que conforman el tipo penal que no requieren el entero conocimiento del autor (elementos normativos del tipo), sino que, basta con que el sujeto tenga la posibilidad de conocer las generalidades de su conducta sin que amerite una reflexión técnico-jurídica. Así también lo entienden Muñoz Conde y García Arán (2010), pues los autores españoles indican lo que sigue: 
Se debe ser parco en la utilización de elementos normativos («acreedor», «insolvencia», «ajenidad», etc.), que implican siempre una valoración y, por eso, un cierto grado de subjetivismo, y emplear, sobre todo, elementos lingüísticos descriptivos que cualquiera pueda apreciar o conocer en su significado sin mayor esfuerzo («matar», «daños», «lesiones», etc.) (p. 256).

Un ejemplo sobre lo prescrito sería el hecho de que no se requiere que en el delito de hurto el delincuente conozca el concepto jurídico de bien mueble o ajenidad de la cosa, sino que, únicamente deberá conocer que está sustrayendo un objeto que no le pertenece.

Respecto de los elementos descriptivos del tipo penal, enseña Roxin (1999) que tradicionalmente se entendía por elementos descriptivos aquellos que reproducen determinados datos o procesos corporales y que además son verificados de modo cognoscitivo por el juez; un ejemplo de ellos podrían ser los términos: animal, edificio, persona, etc. Por tanto, según el tipo penal sub examine, el elemento cognitivo del dolo deberá abarcar tanto los elementos normativos como también los descriptivos del tipo penal.

De igual forma, en el marco del aspecto cognoscitivo del dolo puede originarse un error en razón de la ignorancia o conocimiento imperfecto que se tenga sobre los elementos objetivos del tipo penal, a esto se lo denomina doctrinal y jurídicamente como un error de tipo y su consecuencia sería la exclusión de la imputación dolosa sea que el error fuese evitable o inevitable. Sin embargo, cuando el error de tipo sea evitable, se dejará abierta la posibilidad de que se impute la conducta a título culposo cuando esta figura se encuentre prescrita en el catálogo delictivo, puesto que en el sistema jurídico ecuatoriano poseemos un modelo de tipos culposos de numerus clausus.

Por su parte, el elemento volitivo tiene origen en el presupuesto de que los hombres somos libres y nos auto determinamos en cada decisión que ejecutamos. Ciertos autores entienden que la intensidad del elemento volitivo será 
determinante para identificar cuando estemos frente a un dolo directo, de consecuencias necesarias o eventual. En ese sentido, Rusconi (2016) argumenta que en el dolo directo se recibe una influencia notable del elemento volitivo, puesto que el autor dirige su comportamiento a la producción del resultado y toda su planificación se orienta a ese objetivo. Contrario sensu, respecto del dolo de consecuencias necesarias y del eventual, arguye el autor que el elemento volitivo se presenta con menor intensidad en razón de que el sujeto puede conocer los posibles resultados perniciosos de la conducta, pero su intención no está plenamente encaminada a lesionar los bienes jurídicos.

Para ejemplificar con la teoría de la voluntad: digamos que un chofer conduce en contrasentido y aquello detona en un atropellamiento que cobra la vida de varias personas; para que dicha conducta pueda ser criminalizada a título de dolo, no solo deberá constatarse que el ciudadano conocía que estaba conduciendo a contrasentido, sino que, además deberá corroborarse que efectivamente tenía la intención de provocar dichos atropellamientos. Como es lógico, un supuesto de esta naturaleza trae aparejada la discusión sobre si la conducta es dolosa o imprudente, para ello, la doctrina tradicional se valía de las teorías del consentimiento ideada por Reinhard Frank, que según Ragués I Vallés (1999) en su obra "El dolo y su prueba en el proceso penal" consistía en que "concurre el consentimiento necesario para el dolo eventual cuando, habiendo previsto el autor como posible la realización del tipo, puede afirmarse que habría actuado igualmente de haberla previsto como segura" (p.p. 62 y 62). O a su vez, la doctrina también se valía de la teoría de la indiferencia de Karl Engisch, que según el maestro Roxin (1997), en su obra denominada La estructura de la teoría del delito, se daba "cuando el sujeto da por buenas o recibe con indiferencia las consecuencias accesorias negativas meramente posibles, y sin embargo no cuando considera indeseables esas consecuencias y tiene por ello la esperanza de que no se producirán" (p. 432).

* Teoría del conocimiento o de la representación. - Pese a que la teoría de la voluntad fue absolutamente dominante en gran parte del siglo XX, cada vez con mayor asiduidad la doctri- 
na mayoritaria ha venido desapegándose de elementos psicológicos y sobre todo del aspecto volitivo de la teoría del dolo. Así, por ejemplo, el profesor Sánchez Málaga (2016) en el esfuerzo de proponer una construcción coherente y que resuelva los conflictos clásicos, aduce que “... la elaboración de una propuesta acerca del dolo reside en la necesidad de tomar consciencia de que los enfoques psicológicos se encuentran hoy en proceso de superación” (p. 73), esto es así - dice Sánchez Málaga- en razón de los severos inconvenientes para la constatación de cuestiones inherentes al fuero interno de los sujetos.

Ahora bien, de las teorías que van prescindiendo de los elementos psicológicos, la del conocimiento o de la representación es la más moderada en esta corriente de pensamiento, puesto que descarta de plano la relevancia de elementos volitivos, pero no así el aspecto cognitivo. Bajo esta forma de concebir al dolo, por lo menos debe existir el conocimiento acerca de los presupuestos esenciales del tipo objetivo, y prueba de ello es que, en el análisis de la institución del error de tipo, cuando existe un conocimiento imperfecto o desconocimiento vencible o invencible, la regla es que se excluya el dolo; consecuentemente, constituye un requisito esencial la presencia del aspecto cognoscitivo.

De igual forma, autores como el precitado Sánchez Málaga (2016) aducen que adoptar la teoría del conocimiento acabaría con la innecesaria taxonomía de las clases de dolo, puesto que tanto en el dolo directo, de consecuencias necesarias y también en el eventual, el único elemento que siempre se encuentra presente es el cognoscitivo, ya que, según el entendimiento del autor, en el dolo de consecuencias necesarias no existe ningún elemento volitivo. No obstante, otro grandísimo autor, si se quiere un poco más conservador respecto de la dogmática de la teoría del dolo, esto es, Maximiliano Rusconi (conversación personal en la cátedra de Teoría del delito, primer cuatrimestre, maestría en Derecho penal de la Universidad de Palermo), aduce que todavía es necesario mantener el elemento volitivo del dolo en razón de que es la base para distinguir los distintos tipos de dolo y que es falso que en el dolo de consecuencias necesarias no intervenga la voluntad del sujeto, sino que, esta se presenta con menor intensidad. 
La teoría del conocimiento o también denominada de la representación, adquiere su nombre en razón de las representaciones que pudo llegar a efectuarse quien conocía las particularidades de su conducta. Esta representación no se da sobre la probabilidad de concreción del resultado, sino que, se da sobre la probabilidad de concretarse la realización del tipo y la consecuente vulneración de la norma. Por ejemplo: en el mismo supuesto aludido ut supra, esto es, en el caso del chofer que conduce en contrasentido y que producto de dicha acción produce un atropellamiento masivo, lo único que es necesario constatar para imputar la conducta a título de dolo es que el sujeto conocía que se encontraba conduciendo en contrasentido, pues aquello, según las bases del sentido común, hacía muy probable que se cometa una infracción de tránsito como la efectivamente acaecida.

* Teoría objetiva o estrictamente normativa. - Quien se adentre al estudio de la dogmática jurídico-penal seguramente advertirá un verdadero aluvión de autores con ideología puramente normativista. Hay que reconocer que el funcionalismo sistémico de Jakobs y sus discípulos prácticamente ha colonizado el pensamiento de los autores hispanohablantes y consecuentemente, todo parece indicar que dicho sistema terminará imponiéndose. A mi modo de ver las cosas, este fenómeno puede atribuirse a la imperiosa necesidad populista de ganar en severidad cuando de sancionar se trata, puesto que la corriente normativista tiende a prescindir de elementos subjetivos en la responsabilidad penal de los ciudadanos, y dichos elementos solían encorsetar al poder punitivo del Estado; por lo tanto, adoptar un sistema puramente normativista constituye una herramienta valiosa para el político que pretende aumentar su clientela electoral.

Por otro lado, un detalle no menos importante es que las becas para estudiar en Alemania están generalmente encaminadas al estudio del Derecho penal en las escuelas de filo normativista, consecuentemente, es natural que las ideas del funcionalismo sistémicos se propaguen con mayor celeridad. Ahora bien, con esto no quiero decir que los postulados del funcionalismo radical carezcan de cientificidad, más bien todo lo contrario, pues su desarrollo ha estado en la pluma de 
verdaderos genios. Sin embargo, estimo que dicho modelo no es posible adaptar en cualquier sociedad, pues parece ser que fue pensado para un sistema social ordenado, estricto y muy riguroso en las consecuencias jurídicas por incumplimiento de normas, y evidentemente en nuestro medio, es decir, en América Latina, no estamos preparados para adoptar un sistema de esas características, so pena de correr el riesgo de que terminemos todos encarcelados y no quede nadie para cerrar la puerta desde afuera.

Sin más preámbulo, si del dolo se trata, la corriente normativista no mantiene un criterio uniforme entre sus distintos autores, y esto es natural pues la libertad de pensamiento da pie a la obtención de criterios dispares aun dentro de la misma línea metodológica. Así, por ejemplo, Ragués I Vallés (1999) desde un enfoque normativista moderado, ha seguido los postulados argüidos en su momento por Von Weber que entendía que la corroboración del dolo no dependía de que el delincuente confiese o acepte haber conocido los elementos objetivos del tipo (requisito mínimo), sino que, este podía deducirse a partir de la manera en la que se llevó a cabo el delito y las circunstancias concurrentes, a esta teoría se la denominaba "dolus ex re". No obstante, el autor aludido efectúa ciertas precisiones y finalmente arriba a la conclusión de que existe dolo cuando "a partir del sentido social de un hecho y de las circunstancias que lo acompañan, puede afirmarse de modo inequívoco que un sujeto ha llevado a cabo un comportamiento objetivamente típico atribuyéndole la concreta capacidad de realizar un tipo penal" (p. 353).

Otra teoría normativa del dolo moderada es la defendida por la profesora Ingeborg Puppe (1999), quien argumenta que lo correcto es que sea el Derecho que ofrezca los parámetros para identificar cuando un peligro es lo suficientemente relevante para la realización del tipo y no así, que aquello quede librado a la subjetividad de los individuos. En suma, desde aquel punto de partida la autora se permite diferenciar un peligro de dolo y otro de imprudencia, pues el primero está presente "cuando observado en sí mismo, expresa un método idóneo para la causación del resultado" (p. 147, nota 61). Ahora bien, 
queda en evidencia que bajo esta tesis no interesaría la representación que se haga la persona, sino que, el dato a tomar en cuenta son las representaciones que efectúe una persona razonable según el baremo promedio.

Finalmente, pese a que existen algunas otras teorías normativas moderadas del dolo, es oportuno comenzar a describir algunas de las teorías normativas absolutas, pues tal es el punto de normativización que incluso se piensa en prescindir de la tipicidad subjetiva. En esta línea de pensamiento se puede encontrar a Rolf Herzberg (1987) quien propone analizar la cuestión del dolo como una cuestión de riesgo permitido dentro de la imputación objetiva, es así que distingue entre riesgo descubierto (dolo) y riesgo cubierto (culpa). En referencia al riesgo descubierto, el autor argumenta que se da en aquellos supuestos en los que "no existe fundamentos objetivos para la confianza racional en la no realización del tipo penal." (p. 1464). Sin embargo, pese al discurso estrictamente normativo-objetivo, no es cierto que se prescinda totalmente de elementos subjetivos, pues la confianza racional basada en parámetros objetivos a la que hace alusión el autor necesariamente depende de un proceso cognitivo propio de los seres humanos. Por tanto, si bien para Herzberg no interesan las representaciones del ejecutor de la conducta, implícitamente su argumento denota que la apreciación subjetiva dependerá del criterio de terceros en base a construcciones sociales que cimientan las llamadas reglas "objetivas".

En una línea normativa más radical todavía, Heiko Lesch (2001) argumenta que la pretensión de una imputación subjetiva desdibuja el concepto normativo de la culpabilidad que actualmente es dominante en la doctrina. Además, el profesor Lesch indica que "el dolo, con independencia de que se ubique en la culpabilidad o en el injusto, es una reliquia del antiguo concepto sicológico de culpabilidad y, en tal medida, un cuerpo extraño en una teoría de la imputación que, por lo demás, es puramente normativa" (p. 17).

Ahora bien, dadas las particularidades fundamentales de las teorías sobre el dolo, en lo que sigue corresponde resaltar algunas críticas que la doctrina ha hecho de cada una de ellas. 
Veamos: en primer lugar, sobre la teoría de la voluntad, la opinión dominante ha sido lapidaria al criticar la dificultad casi in extremis de lograr comprobar la existencia del dolo dentro del proceso penal; por ello, según Ragués I Vallés (1999):

(...) una aplicación estricta de la idea según la cual sólo resulta legítimo condenar a un sujeto por delito doloso cuando consigan averiguarse determinados datos psíquicos que concurrieron en el momento de realización del comportamiento objetivamente típico hace imposible cualquier condena por delito doloso" (p. 520).

Asimismo, también es muy criticable basar la distinción entre delito doloso y culposo a raíz de la indiferencia que el sujeto muestre sobre las posibles consecuencias disvaliosas, puesto que aquello, según entiende Corcoy Bidasolo (2008) en su obra El delito imprudente. Criterios de imputación del resultado, no sería otra cosa que criminalizar la personalidad de quien ejecuta la conducta y consecuentemente el principio de culpabilidad se pondría en tela de duda. De igual forma, no hay que minimizar el hecho de que el principio de lesividad también podría verse menoscabado cuando se siga la tesis del consentimiento (teoría de la voluntad), puesto que podría calificarse como dolosos ciertos supuestos en donde exista un peligro objetivo minúsculo y como imprudentes los casos en donde objetivamente se prevea un peligro extremo; es por ello, que autores como Feijóo Sánchez (p. 2002) sostienen que la teoría de la voluntad implica "privilegiar de forma injustificada al autor especialmente temerario frente a otros más prudentes” (p. 31).

En segundo lugar, sobre la teoría normativa u objetiva del dolo, se ha visto en líneas precedentes que aquí se busca prescindir totalmente de los factores psicológicos que concurren en cabeza del ejecutor de la conducta, y más bien, dado que la pretensión es objetivizar el dolo, la tarea se encamina a determinar supuestos fácticos que permitan concluir fehacientemente que bajo dicho contexto el sujeto debía conocer los elementos típicos que la norma prohibía o mandaba. Por tanto, bajo la teoría objetiva del dolo se prescinde de una actividad probatoria encaminada a la comprobación del dolo, y más bien, lo que se 
hace es imputar el conocimiento (dolo) al sujeto que tenía la obligación de conocer. A prima facie esta tesis resulta poco más que problemática, pues prácticamente se estaría diciendo que el ser humano, sea de cualquier cultura, cualquier edad, cualquier formación académica, todos tendríamos la misma capacidad de desenvolvimiento e identificación de conductas y situaciones posiblemente relevantes para el Derecho penal, lo cual personalmente me resulta descabellado. Adoptar una tesis como esta significaría descartar la unicidad de los seres humanos y conllevaría inexorablemente a una automatización del hombre en sociedad.

Y, en tercer lugar, sobre la teoría del conocimiento o de la representación, estoy completamente convencido que es la teoría más cercana a dar en el clavo sobre esta problemática aparentemente irresoluble. Sánchez Málaga (2016) efectúa una analogía para destacar la complejidad de encontrar una teoría que permita concluir inexorablemente que nos encontramos frente a un supuesto doloso, y es por ello que se pregunta: “¿cuándo una persona es calva o cuánto dinero debe tener alguien para ser considerado rico?" (p. 74); por tanto, parece ser un aspecto de la teoría del delito imposible de cuantificar o encasillar por el enorme esfuerzo que conlleva trabajar con elementos subjetivos. Así pues, lejos de aseverar el acierto absoluto de la teoría del conocimiento, sí es posible identificar puntos fuertes que la posicionan como la teoría predominante. Veamos: la crítica probatoria que se le hacía a la teoría de la voluntad parece ser superada, pues en este caso no se requiere probar la intención del sujeto, sino únicamente el conocimiento del peligro que su conducta generaba. Por ejemplo: digamos que A se encontraba en el primer piso de su vivienda y lanza por su ventana un televisor que por casualidad le cae en la cabeza a B que transitaba por el sector, en este caso no es necesario evaluar cuál era la voluntad de A, sino que, basta con que A haya conocido que su conducta ponía en riesgo la integridad física de los transeúntes para que se constate la presencia el dolo.

De igual forma, esta teoría no se choca con la despersonalización de los ciudadanos como sí lo hace la teoría objetiva, puesto que en este caso el conocimiento que deberá imputarse 
no es el de la generalidad de ciudadanos, sino que, es el que efectivamente gozaba el ciudadano que ejecutó la conducta, lo cual significa analizar en cada caso concreto cuán conocedor, cuán formado o cuán lúcido se encontraba el individuo. De esta forma, según mi juicio y pese a que no escapa de críticas, la teoría del conocimiento no solo se ajusta a las exigencias del respeto de la dignidad humana, sino que, también en términos político-criminales resulta conveniente, puesto que no es ni tan severa ni tampoco permite la impunidad.

\section{CONCLUSIONES}

En sí misma, la tarea legislativa reviste de gran complejidad en razón de la multiplicidad de criterios disponibles por los que se puede decantar el legislador al momento de promulgar una Ley. Sin embargo, esto no significa que dicha complejidad deba pagarse en moneda de la coherencia y consistencia normativa, puesto que un mensaje contradictorio a la ciudadanía no genera otra cosa más que caos hermenéutico. Por tanto, estoy convencido de que el legislador envió un mensaje contradictorio al decantarse por la teoría de la voluntad del dolo y en el mismo cuerpo reformatorio permitir que se exhiban a la luz pública a los posibles infractores. En el primer caso legisló bajo los presupuestos de un Estado de derecho, y en el segundo, de forma muy llamativa legisló como un Estado absolutista en donde la represión es el norte.

La teoría de la voluntad del dolo por la que se ha inclinado el legislador ecuatoriano ha sido superada en la doctrina mayoritaria, debido a que a dicha teoría se le puede encontrar inconvenientes por donde se la mire y así ha quedado expuesto en el desarrollo de la obra; por tanto, para el día de hoy, los principales autores de formación europeo-continental han adoptado como correcta la teoría del conocimiento o de la representación. Pese a todo esto, estimo que la teoría de la voluntad del dolo se constituye talvez como la más garantista de entre la amalgama de teorías, puesto que, según sus presupuestos, únicamente se configurará la tipicidad subjetiva cuando el sujeto haya conocido y tenido la voluntad de ejecutar una conducta antinormativa. 
Respecto del primer inciso del artículo ochenta y siete de la Ley Orgánica reformatoria al COIP, entiendo que este viola frontalmente una gama de derechos constitucionales. Además, no solo es una norma en sí misma violatoria de derechos, sino que, además desborda irracionalidad e inconsistencia, puesto que no puede argüirse en el mismo articulado que se reconoce el derecho a la presunción de inocencia de los ciudadanos y al mismo tiempo decir que el ciudadano que sea aprehendido en delito flagrante y acto seguido se califique judicialmente su flagrancia, será expuesto ante la luz pública. Siendo optimista, quiero pensar que esta norma no es producto de un análisis concienzudo, sin embargo, dado el contexto fuertemente punitivista, lo más probable es que una norma de este calibre fue direccionada a satisfacer el clamor de represión característico del grueso de la sociedad.

En términos estrictamente dogmáticos, la teoría de la voluntad del dolo como estandarte de la corriente finalista ha sido completamente superada en la doctrina, hoy en día se encuentran en boga teorías que tratan de prescindir de los elementos cognitivos y además asegurarse de que lo único determinante a la hora del análisis del dolo sean criterios estandarizados (objetivos) con raigambre estrictamente normativo.

En suma, en tanto que el Derecho penal es de acto y aquello trae aparejado la proscripción de la responsabilidad penal objetiva, la exigencia de una teoría del dolo en donde se deba constatar elementos psicológicos es un requisito esencial en la difícil tarea de contención del poder punitivo del Estado, puesto que solo de esa manera nos podemos asegurar de que se sancione al ciudadano de acuerdo a sus posibilidades psíquicas reales y no así, de las que debiera poseer. Adoptar un criterio contrario significaría meter en una misma bolsa a todos los hombres sin que se tome en cuenta las particularidades de cada uno de ellos.

Finalmente, mi querido maestro argentino, el profesor Sandro F. Abraldes me dijo una vez en su cátedra: "no es tarea del legislador decantarse por una de las teorías del dolo" y claro, 
eso es muy lógico si aceptamos que la ciencia del derecho es tan cambiante que las teorías desarrolladas por la doctrina hasta el momento bien pueden sufrir una variación sustancial y de esa manera el juzgador quedaría atado a una decisión legislativa decimonónica y perniciosa. Por tanto, lo más conveniente hubiese sido que el legislador deje en manos de la doctrina y la jurisprudencia el concepto de dolo.

\section{REFERENCIAS BIBLIOGRÁFICAS}

Binder, A. (1999). Introducción al Derecho procesal penal ( $2^{\text {a }}$ ed.). Buenos Aires: Ad-hoc.

Corcoy Bidasolo, M. (2008). El delito imprudente. Criterios de imputación del resultado, segunda edición. Montevideo- Buenos Aires: B de F.

Feijóo Sánchez, B. (2002). El dolo eventual. Bogotá: Universidad Externado de Colombia.

Ferrajoli, L. (2004). Epistemología jurídica y garantismo. México D.F.: Fontamara S.A.

Feuerbach, A. V. (1989). Tratado de Derecho Penal Común vigente en Alemania. Buenos Aires: Hammurabi.

Herzberg, R. D. (1987) NJW. Citado por Ragués I Vallés, R. (1999). "El dolo y su prueba en el proceso penal". Barcelona: Bosch.

Lesch, H. H. (2001). Injusto y culpabilidad en derecho penal. Bogotá: Universidad Externado de Colombia.

Muñoz Conde, F. y García Arán, M. (2010). Derecho Penal Parte General ( 8 a ed.). Valencia: Tirant lo Blanch.

Puppe, I. NK SS 15, n. marg. 61. Citada por Ragués I Vallés, R. (1999). "El dolo y su prueba en el proceso penal". Barcelona: Bosch. 
Plascencia Villanueva, R. (2004). Evolución de la teoría del dolo. México D.F.: Instituto de investigaciones jurídicas de la UNAM.

Ragués I Vallés, R. (1999). El dolo y su prueba en el proceso penal. Barcelona: Bosch.

Roxin, C. (1999). Derecho Penal Parte General, trad. Diego Manuel Luzón Peña, Miguel Díaz y García Conlledo y Javier de Vicente Remesal. Madrid: Civitas.

Roxin, C. (1997). Derecho Penal, Parte general. Fundamentos. La estructura de la teoría del delito, tomo I. Madrid: Civitas.

Rusconi, M. (2016). Derecho Penal Parte General (3 ${ }^{\mathrm{a}}$ ed.). Buenos Aires: Ad-hoc.

Sánchez Málaga, A. (2016). “El dolo: ¿Fenómeno espiritual o atribución normativa?”. Themis, ISSN: 1810-9934.

Welzel, H. (1956). Derecho Penal Parte General, trad. Carlos Fontán Balestra. Buenos Aires: Roque De Palma.

Zaffaroni, E; Alagia, A y Slokar, A. (2002). Derecho penal parte general. Buenos Aires: Ediar.

Recibido: $16 / 03 / 2020$

Aprobado: 12/06/2020

Vicente Vásconez Merelo: Investigador jurídico

independiente. Abogado penalista.

Correo electrónico: vvasconez@hotmail.es

Ciudad: Quito

País: Ecuador 
